\title{
Worked hours, job satisfaction and self-perceived health
}

\author{
Xavier Bartoll ${ }^{1}$ \\ Agència de Salut Pública de Barcelona, Barcelona, Spain and \\ Institut d’Investigació Biomèdica (IIB Sant Pau), Barcelona, Spain.
}

\section{Raul Ramos}

AQR-IREA, University of Barcelona, Barcelona, Spain

\section{Purpose}

To analyse the potential confounding and moderator role of job satisfaction on the effect of working hours on self-perceived health and to analyse the effect of transitions between working hours and job satisfaction.

\section{Design/methodology/approach}

Using longitudinal data for the Catalan economy in 2005-2009, first we run a linear probability random effects model, with self-perceived health as the dependent variable, on one-year lagged job satisfaction, working hours and its interaction. Second, we estimate an ordered logit model to test the effect of transitions to working hours and different levels of job satisfaction on selfperceived health.

\section{Findings}

Short working hours $\leq 20 \mathrm{~h} / \mathrm{w}$ predict good self-perceived health for women. Long working 41$47 \mathrm{~h} / \mathrm{w}$ predict poor self-perceived health among men and women but not for very long hours $\geq 48 \mathrm{~h} / \mathrm{w}$. Interaction effects between working $41-47 \mathrm{~h} / \mathrm{w}$ and job satisfaction levels were found

\footnotetext{
${ }^{1}$ Corresponding author. xbartoll@aspb.cat
} 
for men and women. Improvements in job satisfaction for health are reduced when working long hours. For employees, a decrease in job satisfaction may suggest a health risk except if hours also reduce.

\section{Social implications}

Workplace practices aimed at gaining flexibility in working hours may be offset, in terms of health outcomes, by lower job satisfaction. Flexible working hours from the employees' side should be favoured to face reductions in job satisfaction.

\section{Originality/value}

The novelty of this paper is that highlights differential effect of job satisfaction in the relation between working hours and health status. 


\section{Introduction}

There is a considerable heterogeneity between employees regarding the combination of working hours with different job and workplace characteristics. For a high share of workers, working hours differ from the standard working week, with $20.5 \%$ of workers employed part-time and 40\% with longer working hours than standard (Eurofound, 2017a). At the same time, according to some estimates, $20 \%$ of European workers are employed in either low- or high-quality jobs (Eurofound, 2017b).

In this research we explore the interrelation between working hours, job satisfaction and health outcomes. Previous literature has identified that long working hours have adverse effect on health, but the observed association might be weakened by the omission of relevant variables such as gender and job characteristics (van der Hulst, 2003; Bannai and Tamakoshi 2014; Ganster et al., 2018). In fact, high job control or high rewarding jobs can provide a surplus of job satisfaction that compensates for the adverse effects of long working hours vanishing its adverse effect on health status. These active jobs can even increase the supply of working hours without necessarily incuring on health loses (Ng and Feldman, 2008). Alternatively, health gains due jobs of better quality can be offset by losses through longer working hours. Therefore, the adverse effect of working hours on health can be moderated by job satisfaction, i.e., the effect may differ depending of high or low job satisfaction levels. There is no a priori clear answer based on theory but the question remains rather an empirical one and depends on the strength of the associations between working hour, job satisfaction and health status. To date, most literature has considered separately the effect of working hours and the job satisfaction on health outcomes, while neglecting the combined effect of both. We try to fill this gap by focusing on the potential confounder and modifier role of job satisfaction on the effect of working hours on health status. The analysis is performed in levels and in transitions. By 
analysing transitions, we also address the issue of internal flexibility effects on health. We construct a job satisfaction index that incorporates key elements highlighted by previous reports (for a summary of proposals see Holman (2013)) and we focus on self-perceived health, an indicator that captures both physical function and psychosocial problems (Mavaddat et al., 2011), and is a valid predictor of morbidity and mortality (Ilder and Benyamini, 1997; Pietz and Petersen, 2007).

In this study, we use longitudinal data from Catalonia between 2005 and 2009 for with available data on satisfaction with job dimensions and health outcomes are recorded. The panel is the only one in Spain with this data available, as the Spanish version of the EUSILC panel does not include information on job satisfaction. Catalonia, as the rest of the Spanish state, is characterized by segmented labour markets, high job presentism and low productivity, in a context of the South European well-fare state typology of poor public provision of family services. Catalonia is located in the north east of Spanish state and has a population of 7 million people. It has mainly industrial economic activity and a gross domestic product per capita of $\sim € 28,000$. The objective of this study is to analyse the potential confounding and modifier effect of job satisfaction and working hours on self-perceived health. We also analyse the effect on changes in self-perceived health of transitions between jobs demanding different working hours and providing different levels of job satisfaction.

The rest of the paper is organized as follows: first, the background section sets the issue in the context of the occupational models, followed by a review of the literature on job satisfaction and health on the one hand, and working hours and health status, on the other. Next, the empirical strategy in relation to the measures of both, job satisfaction and health status is described, as well as the econometric model proposed to analyse its relation either in levels as in transitions. The methods section describe the target population, variables and the empirical setting, being 
followed by the presentation of the obtained results. Finally, we conclude with a global discussion and limitations of our analysis.

\section{Background}

Two prominent psychosocial occupational models, the Demand Control Support (DCS) and the Effort Reward Imbalance (ERI) models (Kararek and Theorell, 1990; Siegrist, 1996), predict that jobs that provide higher autonomy and control or higher rewards not only play a protective role against increasing physical and psychological pressure but also provide a feeling of success, merit, and self-efficiency. This active job type contrast with jobs that experience high demands and a low level of decision-making latitude, low levels of social support or job security, unsatisfactory organizational climate, and unfair rewards tended to provide higher risks of stress and job dissatisfaction. Longer working hours may reinforce job dissatisfaction for this kind of stressful not rewarding jobs, but also decrease job satisfaction of the active rewarding jobs due to increasing fatigue or diminishing the possibilities of a better working-life balance. But, it is also likely that employees engaged in satisfying jobs may offer more working hours and dissatisfied workers offers less, so that, there is no a priori clear sing in the association also between job satisfaction and working hours. In turn, both job satisfaction and working hours have an effect on health outcomes.

\section{Job satisfaction and health}

Overall job satisfaction can be taken as a proxy for satisfaction with specific working conditions (Mora, 2008). There is vast literature on the effects of job satisfaction on health outcomes. The meta-analysis from Faragher of almost 500 studies identified an association between job dissatisfaction and poor health outcomes, with a stronger correlation for psychosocial problems (above 0.4) and to a lesser extend for physical illness (around 0.29) (Faragher et al., 2005). An adverse overall working conditions effect on mental health has also been reported across European countries, where more demanding jobs and restricted autonomy leading to higher probability of mental health problems (Cottini and Lucifora, 2010). The evidence of a positive 
effect of job satisfaction on health is also confirmed using more objective health data such as health system contacts or daily living limitations (Fischer and Sousa-Poza, 2009) (Datta Gupta and Kristensen, 2008) but the effect depends on the working hours regime.

\section{Hours of work and health}

Several systematic reviews summarize an extensive literature on the effects of long working on health but recent reviews have stressed some shortcomings of the earlier research such as the omission of working conditions and the lack of longitudinal studies. For instance, the reviews by Sparks et al. (1997), Van der Hulst (2003) and Bannai and Tamakoshi (2014) identified a positive association between long working hours and a variety of physiological and psychological health problems (cardiovascular disease, diabetes, subjectively reported physical health, subjective fatigue, and sleep disturbances). While, in contrast to these results, two other reviews found weak or inconsistent support for an association between long working hours and mental health measures. Fujino et al. (2006) found an inconsistent association between working hours and mental health and depression. Watanabe et al. (2016) performed a systematic review and meta-analysis found that overtime work was only associated with a small, non-significant increase in the risk of depressive disorder. In the same lines, Ganster et al. (2018) highlighted a possible bias in previous research that rarely uses longitudinal studies and the potential omission of some key variable(s), as gender and working conditions among others. Indeed, if long working hours result in socioeconomic advantages, this may produce positive health outcomes that counterbalance the negative effects (Ganster et al., 2018). One study has also found that having a good job is positively correlated with the amount of working hours (Ng and Feldman, 2008). In fact, employees motivated by favourable working conditions appeared not to be fatigued by overtime (Beckers et al., 2004).

Part-time work is generally characterized by poorer working conditions, lower wages per hour and fewer prospects (O’Dorchai et al., 2007; Manning and Petrongolo, 2008; Bardasi and Gornick, 2008). Surprisingly, the adverse conditions of part-time work (O’Dorchai et al., 2007; 
Manning and Petrongolo, 2008; Bardasi and Gornick, 2008) do not always result poorer health outcomes. Two studies on atypical employment found no association between part-time employment and health (Rodriguez, 2002; Bardasi and Francesconi, 2004). Short working hours may also increase wellbeing because of a better work-life balance or being able to enjoy other social activities (Booth et al., 2008; Booth and van Ours, 2013). For instance, Robone et al. (2011) found a positive and statistically significant relationship between health and having a part-time job among employees who reported being satisfied with the number of hours they worked and those who did not have children, with clear differences according to gender.

\section{Empirical strategy}

Job satisfaction is one of the most used subjective summary measures to evaluate well-being at work (Böckerman, 2004; Clark, 1998, 2001; Clark \& Oswald, 1996; Frey, 2008). If proper instruments for job satisfaction analysis are not available (see Hora et al., 2018 for a summary of instruments), even a single-item measure has also shown an acceptable validity and reliability values according to the literature (Dolbier et al., 2005; van Saane et al., 2003; Wanous et al., 1997). Nonetheless a preferable measure would be to ask employees the degree of job satisfaction among several dimensions, based on theory, and ask for their relative importance. If these self-reported weights are not available, a common practice used in the literature, is to aggregate satisfaction across the different job dimensions into indexes according to some weighting strategy (see Green \& Mostafa, 2010 for a brief summary). In particular, Holman and Cleveland propose weights based on the proportion of variance explained by each dimension (Holman and McClelland, 2011). In similar lines, this investigation uses Confirmatory Factor Analysis (CFA) to construct a job satisfaction index summarising different dimensions rather than relaying just on a single-item overall self-reported job satisfaction measure. The factor loads in the CFA model can be interpreted as correlations of each dimension with the (latent) job satisfaction index, or, if squaring the loads, as the share of variance explained by each dimension. An advantage of this approach is that the CFA accuracy can be assessed by standard goodness of fit measures. For instance, this technique has been recently used to describe 
changes in the working conditions during the economic crisis in Spain as a tool for estimation a more robust measure of job satisfaction (, (Bartoll \& Ramos, 2019, Díaz-Chao et al., 2014)

Measuring health is a challenging issue due to its multidimensional nature. Often, the choice is limited by the availability of the data as in this investigation. A problem with routinely labour official surveys and statistics is that they rarely collect sufficient data on working conditions and health outcomes at a time. Rich labour statistics are scarcely informative on health problems and vice versa. In this investigation we use subjective self-perceived health as a measure of general health status. Although work-related health problems are primarily associated with psychosocial problems, there is no specific available mental health instrument in the analysed panel. However, self-perceived health has proven to be a valid and synthetic indicator of disease burden that correlates with physical function, mental distress and well-being (Martikainen et al., 1999). (Simon et al., 2005) (Mavaddat et al., 2011), and is a valid predictor of morbidity and mortality (Ilder and Benyamini, 1997; Pietz and Petersen, 2007).

\section{Working hours, job satisfaction and self-perceived health in levels}

Estimating a panel with ordered self-perceived health as the dependent variable and the presence of interaction terms faces also several empirical challenges. Different alternatives have been proposed for estimating ordered logistic fixed effects (Baetschmann et al., 2015; Muris, 2017). However, fixed effects results in a dramatic loss in sample size which leads to poor estimates, in this case, the Hausman test (applied to the dichotomized self-perceived health) favours random effects. Moreover, fixed effects drops time-invariant covariates, such as education level, which can be problematic because there is evidence that that workers with disadvantaged statuses report higher satisfaction with the same jobs than those with advantaged statuses (Perales \& Tomaszewski, 2016). Additionaly, as health status is a recursive phenomena, we condition for lagged self-perceived health, so that the estimation based on random effects by maximum likelihood is the natural alternative. It has the advantatge that all observations of the unbalanced panel contribute to the parameters estimation. It is also possible 
to adress the assumption of independence between the random effect and covariates to obtain a correlated random effects apllying the correction proposed by Mundlak (1978) and Wooldridge (2005) (the unobserved individual random effect depend on a linear combination of the mean values of the socioeconomic time-variant covariates and on the initial value making the unobserved effects fully specified. Nonetheless, as highlighted by Ai and Norton (2003) and Norton and Wang, (2004), the interpretation of the interaction term in non-linear models is problematic. First, the partial effect for an interaction term could be non-zero even if the directly estimated coefficient of the interaction term is zero. Second, we cannot rely on standard tests of significance, and the magnitude and sign of the interaction may depend at different values of the covariates. Therefore, to compute the magnitude of the interaction effects it is necessary to compute the cross derivative (or differences). For instance, Robone et al. (2011) uses this setting analysing the interaction effect of binary type of contract and working conditions on health outcomes. Unfortunately for interaction terms of higher order the computation can be very cumbersome. On the other side, it has been shown that the linear probability model (LPM) performs optimally (Ferrer-i-Carbonell and Frijters, 2004) and that differences between ordinal and cardinal data are minor. Importantly, the results directly can be interpreted in marginal terms and are more readily interpretable than the log-odds ratios. Given the low skewness of our dependent variable, in this investigation we apply LPM and compared with the correlated corrected random effects model.

Transitions in working hours, job satisfaction and self-perceived health

Prior studies have mainly focus on the health effects of job transition across employment status (employed to unemployed or vice versa) or across firms. However, claims for labour flexibility, especially since the economic crisis, has led to a spread of internal flexibility at firm level what implies changes at the workplace mainly in the form of wage flexibility and in working hours flexibility (the so called 'numerical flexibility') which can also potentially lead to changes in working activity or in other job characteristics (“qualitative or functional flexibility”). According to European estimates, these forms of internal flexibilization exceed that of external 
flexibilization for most European countries (Tangian 2007). To further exploit the longitudinal structure of the data, we analyse the transitional states between hours and the job satisfaction on health status including changes of jobs across firms but also internal-flexibility. Prior research on transitions to jobs of poorer quality finds higher health risks Graetz (1993)(Llena-Nozal, 2009) and even experience greater declines in psychological health than unemployment (Butterworth et al., 2011). This adverse effect appears to be larger for psychological rather than physical health and for older men (Gebel and Voßemer, 2014)(Unger et al., 2018). Two exceptions are Gebel and Voßemer (2014) and LaMontagne et al., (2014) that using panel data for Germany and Australia find no health difference when getting a job either permanent or temporary contract. These different results depend on the possibilities of reemployment for older workers and the job quality of these temporary employments. From the literature on the effect of working hours on health outcomes, we can infer that working longer hours a prior decreases health outcome. However, rarely changes in hours exclude changes in job quality, for instance it has been found that internal numerical flexibility in the form of part-time tend to come along with reduction in wages, but it is also congruent to increase working hours and the commitment with the firm goals (van der Meer \& Ringdal, 2009). Therefore, it is justified to consider the combined effect of both numerical and qualitative flexibility effect on health. To our knowledge, our study is the first exploring the combined effect of changes in hours and job satisfaction. To analyse transitions, it is applied e apply first differences to hours, job satisfaction and self-perceived health so that time-invariant characteristics vanishes. We also account for changes in type of contract and estimate an ordered logistic model over the first differences.

Considering the three pieces altogether, the positive effect of job satisfaction on health and the negative effect of (long) working hours on health, we contribute to the existing literature by first analysing if the positive effect of job satisfaction differs with working hours and, second, assess the effect on health of variations in both, job satisfaction and working hours irrespective of the working hour level. 


\section{Population and variables definition}

\section{Population}

The Social Inequalities Panel from the Jaume Bofill Foundation is the first longitudinal survey in Catalonia. It was derived from a statistically representative sample of Catalan households. selected randomly by stratified sampling in multiple stages, with a systematic random selection of the first sample units (census tracts) and simple random selection of addresses. Our analysis considers five consecutive waves from 2005 to 2009 of salaried employees aged 25 to 64 years for whom information on working conditions is available, our total sample comprises 6393. Since we condition health on values of the previous period, 1310 observations in the first year are left, Moreover, the panel is highly not balanced and some individuals do not have observations for the whole years which reduces to 3695 individuals. Additionally, 455 cases have missing values in some variables which leaves 3240 for analysis (1513 men and 1727 women). Inverse probability weighting (IPW) is applied to account for missingness based on demographic and socioeconomic variables (Seaman \& White, 2013).

\section{Self-perceived health}

Participants were asked about their perceived general health using the question: "How is your health in general? With five possible answers: "very good”, "good”, "regular”, "bad” and "very bad”. Due to the low sample in the lowest categories, "regular”, "bad” and "very bad” was collapsed in a "poor" health category.

Health transitions were calculated by subtracting two consecutive states of the five categories of health status, whereby three possible changes were obtained: equal, if there were no changes in 
health status; improvement if there was a transition from a lower level to a higher level; and worsening, if there was a transition from a higher to a lower level.

\section{Working hours}

Participants were asked about the number of hours they worked per week. Very short working hours were categorized as $\leq 20$ hours per week (h/w), short hours as 21-34 h/w, standard hours as $35-40 \mathrm{~h} / \mathrm{w}$, long hours as $41-47 \mathrm{~h} / \mathrm{w}$ and very long hours as $\geq 48 \mathrm{~h} / \mathrm{w}$ according to the European Community Working Time Directive (2003/88/EC).

Working hour transitions were simply calculated by subtracting number of working hours at time t-1 from number of working hours at time $t$ and then categorize as more, less or equal hours.

\section{Job satisfaction}

The job satisfaction index is based on five key common dimensions: satisfaction with salary, satisfaction with working activity (Sousa-Poza and Sousa-Poza, 2000), satisfaction with the relationship with colleagues, satisfaction with the relationship with superiors (Siegrist, 1996), and satisfaction with working space. Participants were asked about the five dimensions in a five-item Likert scale from "very high" to "very low".

We performed a confirmatory factor analysis with job satisfaction as the latent variable expressed in the five dimensions of satisfaction as described above. A key condition for analysing job satisfaction over time is to verify the minimum requirement of invariance in form and factor loadings (weak invariance) between years by comparing the significance of the Chisquare among free and constrained parameters. Standardized factor loads, shown in Table A2, (setting the variance of the latent factor to 1) can be easily interpretable as the correlations between the factor and the latent job satisfaction variable so that they explain a larger share of 
the latent variability. All factor loads are significant as well as the covariance between support from colleagues and superiors. Larger correlations are found for support from superiors and satisfaction with the activity, followed by satisfaction with work space, and to a lesser extent by satisfaction with salary and support from colleagues. Our confirmatory factor analysis showed satisfactory goodness of fit measures (Root Mean Square Error of Approximation (RMSEA) 0.047; Confirmatory Fit Index (CFI) 0.984; Standardized Root Mean Residual (SRMR) 0.018, compared with the common standard criteria (RMSEA lower than 0.08; CFI above 0.90; SRMR lower than 0.04). We used this model to predict the scores of the latent variable for the job satisfaction index to be used as input in the remaining analysis.

Job satisfaction transitions were calculated by subtracting two consecutive job satisfaction index scores. As the index is a continuous variable, obtained values can be positive, negative and zero, showing that job satisfaction has improved, worsened or kept equal between the two periods. As the number of individuals where job satisfaction is exactly the same after the transition is very reduced (62 men and 76 women), we have decided to exclude them for the analysis of transitions. However, robustness checks considering this additional category have yield similar results that are available from the authors on request.

\section{Socioeconomic variables}

Socioeconomic controls include age grouped into two categories: 26-45 and 46-64; civil status as married vs non-married; number of children under 16 years old; type of family; education level in three categories (university degree, secondary and primary or less); place of birth (Catalan, from the rest of Spain, and others); type of contract (permanent, temporary, and others); occupation (8 categories); household net equivalent income in tertiles; firm economic activity (10 categories) and size of municipality in terms of inhabitants (6 categories). Additionally, satisfaction with life recorded in three categories was used as a proxy for personal traits that may also affect individual evaluations of subjective work-related emotional states (Judge et al., 2002). 


\section{Empirical setting}

Hours of work, job satisfaction and self-perceived health in levels

In order to consider the potential confounding and moderator role of job satisfaction on working hour effects on self-perceived health, we estimate a dynamic linear probability model (LPM), with self-perceived health as the dependent variable and one year lagged values for working hours, job satisfaction and its interaction as the main independent variables. Lagged values are used to avoid reverse causality, that is, to discard that contemporaneous poorer self-perceived health had an impact on contemporaneous job satisfaction. Moreover, since health status is a recursive phenomenon, we also include one year lagged self-perceived health as an explanatory variable so that the potential effects are interpretable as changes in self-perceived health.

Let $\mathrm{s}_{\mathrm{it}}{ }^{*}$ be the latent (unobserved) self-perceived health of worker $i$ at time $t$, where $\mathrm{i}=1, \ldots, \mathrm{N}$ and $t=2005, \ldots, 2009$. $s_{i t}$ takes the value 2 if the latent variable falls under the 'poor' category, 1 for 'good' and 0 'very good' categories. The estimated model follows the expression:

$s_{i t}=\alpha_{i}+\lambda s_{i t-1}+\delta_{1} h_{i t-1}+\delta_{2} j s a t_{i t-1}+\delta_{3} h_{i t-1} * j s a t_{i t-1}+\beta x_{i t-1}+\pi_{1} h_{i o}+\mu_{t}+u_{i t}$

where $s_{i t-1}$ stands for self-perceived health lagged on period, $h_{i t-1}$ is the lagged working hours and $j_{s a t} t_{i-1}$ is job satisfaction, $h_{i t-1} * j s a t_{i-1}$ corresponds to the interaction term, $x_{i t-1}$ is the socioeconomic variables, $h_{i o}$ the initial self-perceived health, $\alpha_{i}$ is the random unobserved effect and $u_{i t}$ is the serially idiosyncratic uncorrelated error term. The job satisfaction and its interaction term with hours of work are sequentially introduced to the base model with hours and the rest of the covariates. As a robustness check satisfaction with life was added as a covariate.

Transitions in working hours, job satisfaction and self-perceived health 
We also estimate a generalized ordered logit model (Williams, 2006) for health transitions (selfperceived health improving, remaining equal or worsening) with six combinations of transitional states between working hours (higher, lower or equal) and job satisfaction (higher or lower) as independent variables, controlling for changes in temporary contract employment.

$\Delta s_{i t}=\delta \Delta h_{j s a t}{ }_{i t}+\Delta t e m p_{i t}+\xi_{i}(3)$

Where $\Delta s_{i t}$ stands for self-perceived health in the three transitions, $\Delta h j o s a t_{i t}$ for the transitional states between the combined variable for working hours and job satisfaction, $\Delta$ temp $p_{\text {it }}$ controls for changes in temporary contract employment, and $\xi_{i}$ is the idiosyncratic error term. As a robustness changes in satisfaction with life was added as a covariate.

The ordered regression assumes proportional odds irrespective of how values of the ordinal dependent variable are grouped. As this parallel assumption was rejected (Brant, 1990), we applied a generalized ordered logit model (gologit) (Williams, 2006). The gologit model simultaneously estimates as many logit regressions as values of the ordinal variable minus one. In particular, we apply a partial proportional odds model, in which some coefficients of the regressions are constrained to be the same for the variables that do not violate the parallel assumption. The advantage of doing so is that this reduces the number of coefficients to be interpreted compared to the unconstrained or multinomial regression. Marginal effects of transitions on the probability of poor self-perceived health are reported.

For both models, computations apply individual sampling weights from base year 2005 corrected by the IPW and extended for the subsequent waves in the longitudinal analysis, as recommended in previous studies (Andreass, 2013). Full details about the econometric specification of both models and the estimation procedures applied are available from the authors on request. 


\section{Results}

Table 1 shows a summary of selected descriptive statistics for the key variables in our analysis. The standard working week is the most common schedule for men and women $(82.1 \%$ and 68.4\%, respectively). Working hours larger than $41 \mathrm{~h} / \mathrm{w}$ are more common among men (10.7\%), while shorter hours are more common for women (28.4\%). Men and women report $82.6 \%$ and $80 \%$ of good self-perceived health (excellent and good) but only $53.5 \%$ of women in $\geq 48 \mathrm{~h} / \mathrm{w}$. The distribution of job satisfaction index shows a lower proportion of job satisfaction above median for men at $\leq 20 \mathrm{~h} / \mathrm{w}$ and $\geq 48 \mathrm{~h} / \mathrm{w}$. Conversely, job satisfaction decreases with hours for women.

[insert Table 1 around here]

The effect of working hours, job satisfaction and its interaction on self-perceived health in levels Table 2 reports the marginal estimates of the LPM odds ratio of the dynamic ordered logit regression for changes in poor self-perceived health on working time (base model), job satisfaction (adjusted model) and with its interaction term (interaction model). In the base model, men working long hours (41-47 h/w) are weakly associated with changes of poor selfperceived health in next period, but surprisingly, working very long hours ( $\geq 48 \mathrm{~h} / \mathrm{w}$ ) lowers this probability $(-0.17)$. For women, working very short hours $(\leq 20 \mathrm{~h} / \mathrm{w})$ is protective $(-0.11)$ but working long hours (41-47 h/w) worsens health status (0.21). Job satisfaction index in the adjusted model lowers poor self-perceived health for men in the standard 35-40 h/w (-0.16) but not for women. Adjusting for job satisfaction leaves the effect of hours almost unaltered for men and women. The inclusion of the interaction term shows that one unit increase in job satisfaction index increases poor self-perceived health among men working $41-47 \mathrm{~h} / \mathrm{w}$ compared to working 35-40 h/w, that is, the favourable effect of job satisfaction among men in $35-40 \mathrm{~h} / \mathrm{w}$ (-20\% less probability of poor health) is diminished when working $41-47 \mathrm{~h} / \mathrm{w}$ (by 31\%). So that, the presence of job satisfaction widens the difference among long working hours 
and the standard schedule for a given level of job satisfaction. The interaction effect for women working $41-47 \mathrm{~h} / \mathrm{w}$ also points to a worsening of health status compared to the standard working schedule, but the association is weaker. No significant interaction term is observed for men and women working $\geq 48 \mathrm{~h} / \mathrm{w}$. The robustness check of additionally controlling for life satisfaction generated equivalent results (data not shown).

[insert Table 2 around here]

The effect of transitions in working hours and job satisfaction on changes in selfperceived health

We evaluated whether transitions between categories of working hours and job satisfaction are associated with changes in self-perceived health. It is worth noting that transitions across firms are only $6 \%$ of the total transitional states in the sample (data not shown), so that results on transitions are mainly attributable to internal flexibility. Table 3 reports the frequencies and the marginal odds ratio for each of the six transitional states considered. The most common transition was remaining in the same category of working hours ( $75 \%$ of all transitions), with little differences between improved and worsening job satisfaction. For men and women employees, the probability of reporting worse self-perceived health was higher among those who worked more hours with reduced job satisfaction ( 0.21 and 0.11 among men and women, respectively). Conversely, no working more hours but improving job decreases poor health for women (-0.08). Working a similar number of hours but having a lower level of job satisfaction reduces self-perceived health for men (0.06), but results were not statistically significant for women. Interestingly, transitions to lower job satisfaction in combination of less working hours did not worsened self-perceived health. Again, the robustness check of additionally controlling for life satisfaction generated equivalent results (data not shown).

[insert Table 3 around here] 


\section{Discussion}

A first result of this research is that very short working hours are protective for women only but long working hours predicts poorer self-perceived health for men and women working 41-47 $\mathrm{h} / \mathrm{w}$, surprisingly, working $\geq 48 \mathrm{~h} / \mathrm{w}$ is protective for men only. Second, job satisfaction scarcely confounds but modifies the effect of working hours on health status for men but to a lesser degree for women. Third, the longitudinal structure of the data allows us to confirm that moving to a job that provides lower satisfaction has a negative effect on health status, except if the number of working hours also decreases.

The effect of working hours, job satisfaction and its interaction on self-perceived health in levels Despite the low sample size in some categories when disaggregating by gender, we could identify the adverse effects of long working hours (41-47 h/w) on health for men and women. This result is in concordance with beforementioned systematic reviews. The novelty is a clear discontinuity for men at this cut off point of very long hours $\geq 48 \mathrm{~h} / \mathrm{w}$. We must bear in mind that a higher proportion of jobs working longer hours are concentrated in real estate, commerce, construction and agricultural activities, which are paid in greater proportion by commission or piecework. As a consequence, we hypothesize that the voluntariness in the long hours of work can explain this apparent surprising result, in the sense that it is the gap between the actual and desired hours to work what is relevant in terms of health status, so that involuntariness in long working hours is what worsens health status (Bassanini \& Caroli, 2015). Recent estimates across EU28 find that only overemployed men and women who involuntarily work $\geq 48 \mathrm{~h} / \mathrm{w}$ associate with poor well-being but not those who desired to work $\geq 48 \mathrm{~h} / \mathrm{w}$ (Bartoll and Ramos, 2020). In our results, the non-significance for women working $\geq 48 \mathrm{~h} / \mathrm{w}$ could be due to a threshold election. One study for Australia identifies a lower threshold of 38h/w for women once domestic and care work are taken into account (Dinh et al., 2017). The protective effect of working very short hours on self-perceived health for women would confirm previous findings (Booth et al., 2008; Booth and van Ours, 2013) . This result may be due to difficulties 
with work-life balance for women, while men tend to participate less in homecare and work longer hours. The need for policies aimed to improve a better work-life balance is evident when compared to some Nordic countries. These countries are characterized by stringent norms of equal treatment that incentivize engaging in part-time work, which in turn lead to lower or no difference in health effects with standard or long working hours (Bardasi and Gornick, 2008; Hardoy and Schøne, 2006; Halldén et al., 2012). For instance, Bartoll et al., (2014) show that men and women in part-time in Southern Europe have lower job satisfaction compared to fulltime workers but not those in Scandinavian countries. Moreover, men in part-time in Southern Europe experience psychosocial problems but not those in Scandinavian counties.

Our data also suggests that job satisfaction significantly predicts improvement in health status among men only. This result was expected, but the non-significance result for women deserves attention. Although women experience poor health outcomes that men, some authors have pointed out that self-perceived health can be less accurate for women than for men (Benyamini et al., 2000). Gender differences in job satisfaction have been attributed to women having lower expectations about work and focusing different aspects of work, less on wages and more in flexibility schedules, in the context of the social division of labour (Hodson, 1989; Clark, 1997) (D’Addio et al., 2007). Regarding the potentially confounding role of job satisfaction in the association between hours and self-perceived health, our results show very moderate confounding effect in contrast with larger effects detected across EU28 (Bartoll and Ramos, 2020). The reason for this different result is the low association of hours and job satisfaction due to the low variability in hours. Job satisfaction and working hours are two quite independent phenomena in health determination against the recent warnings of Ganster et al. (2018) and Ng and Feldman (2008), according to which the heterogeneity in the association between working hours and health status could be explained by possible confounding factors such as the type of work or the working environment.. More interestingly, the presence of job satisfaction more clearly widens the adverse health effect of hours of work between long working hours (41-47 $\mathrm{h} / \mathrm{w}$ ) and the standard schedule. For this working schedule, the adverse effect of working hours 
on health dominates over the positive effect of job satisfaction. The situation is different for those working very long hours $(\geq 48 \mathrm{~h} / \mathrm{w})$. In this case, there is no negative effect of working hours so that the positive effect of job satisfaction still prevails. Again, we hypothesis that voluntariness on working hours may explain this result. Empirical evidence across EU28 find similar results for interaction with job rewards, conversely the interaction with job intensity decreases well-being (Bartoll and Ramos, 2020). The differential effect of job satisfaction across working hours is a contribution of our investigation. This significant results may shed some light on the previous mix findings of hours of work and health (van der Hulst et al., 2003; Bannai et al., 2014; Ganster et al., 2018). Previous attempts to find adverse effect of long working hours on health for the same Catalan study population that no distinguished from very long hours or do not take account the voluntariness of work fail to identify these effects (Artazcoz et al., 2007).

It is worth mentioning that in order to deal with reverse causality, we have regressed health status on one-year lagged values of our variables of interest. The use of lagged labour characteristics is a common practice in the related literature (Bardasi and Francesconi, 2004; Robone et al., 2011; Butterworth et al., 2011). However, current job satisfaction is probably related to actual health outcomes for men and women, if the combined effect of worked hours and job satisfaction have an immediate impact on health outcomes, then including lagged values instead of contemporaneous one would not allow to capture this effect. For instance, Moscone et al. (2016) uses firm level information in order to construct valid instruments to deal with the endogeneity problem in a similar context. However, this kind of information is not available in our dataset. This is a limitation of the first part of our study.

The effect of transitions in working hours and job satisfaction on changes in selfperceived health 
We have just seen that the favourable effect of job satisfaction on self-perceived health diminishes with long hours 41-47 h/w. When analysing transitions, we look at effect of changes irrespective of a specific working schedule. We have to bear also in mind that in our sample only $6 \%$ of the transitions correspond to changes across firms, so that the interpretation of transitions can be attributable to internal flexibility. Increasing working hours but at the same time increasing job satisfaction leads to a net positive effect on health if the positive association of job satisfaction with health is stronger than the negative association of working hours. The result obtains for men and women although only for women is significant. These transitions seem to correspond to the active type o jobs that demands more commitment with firm but also are more rewarded. Women, that in general have more precarious and part-time jobs, would benefit more from an upgrading job. Conversely, transitions that provide also more working hours but with lower job satisfaction are the worse combination in terms of health status. The second worst change corresponds to transitions to working equal hours but with lower job satisfaction, although are only significant for men. These worst transitions involve lower job satisfaction probably attributable to passive, stressful or not rewarding jobs. Previous literature has not explicitly dealt with job satisfaction, but points to it as an important factor. For instance, Graetz (1993) reported a higher risk of poor mental health among dissatisfied workers and lower levels of mental health among satisfied workers. There is some asymmetry between the adverse health effects of changing working hours and the level of job satisfaction. In particular, working less hours do not lead to a significant change in self-perceived health even if job satisfaction increases, that is, losing job satisfaction has a larger effect than gaining it. These results are consistent with those of a study among manual workers in the USA when analysing transitions from unemployment to employment (Morefield et al., 2011). The positive effects of moving into work from unemployment were not as great as the negative effects of job loss (Thomas et al., 2005; Flint et al., 2013).

In sum, numerical and qualitative internal flexibility should be analysed at a time because its differential impact on health status. The final net effect depends on the strength of the 
association between working hours and job satisfaction and each of them with health status.

Data show that qualitative internal flexibility can offset numerical flexibility effects. Our results dependent on context and extrapolation to other labour market setting should be done with care. Internal flexibility is usually driven by employer requirements, which may lead to reductions in job satisfaction and poorer health outcomes. Our results can contribute in promoting social dialogue by suggesting flexible working time on the employee side that increase job satisfaction such as the compressed working week, introducing the right-to-request flexible working time, or the time saving account among others novel measures.

\section{Limitations and conclusion}

The main strength of this study is that our approach controls for unobserved individual heterogeneity together with a wide range of controls, while at the same time introducing lagged covariates in order to minimize reverse causality problems. However, there are also some limitations. For instance, Conway et al. (2017) reported non-linear adverse health effects of long working hours of $\geq 52 \mathrm{~h} / \mathrm{w}$ among workers in the USA that we have not considered in our analysis. In fact, the sample size is quite limited for some categories, especially for individuals working more than $48 \mathrm{~h} / \mathrm{w}$, where higher health risk could be expected. Although self-perceived health is widely used measure, the analysis would have benefit with the inclusion of other health outcomes such as absenteeism and psychosocial problems or other chronic disease that were not available and could be more sensitive for women health than self-perceived health. While our job satisfaction index fits satisfactory, it has been alleged that job dimensions are more informative for policy recommendations, as such dimensions may impact health outcomes in a different way and the trade-off between them be very limited. For instance, there are other potentially relevant aspects of the overall psychosocial working environment such as shift work and work-family balance, that were not included in the analysis due to data limitations. Moreover, changes in job satisfaction index could be alternatively defined as the difference in scores in an interval range rather than the simple difference, in that case more sample size 
would have been needed. There are also contextual factors that could have affected the results. Labour market is subject of recurrent labour reforms, especially in Spain in the last years and amid the economic crisis (2006, 2010, 2012 and the ongoing one in 2020). The labour reforms of 2006 aimed at reducing the segmented labour market had a very low impact and scarcely have affected the work environment and trends. More important effect, during the studied period, may have had the economic crisis of the late 2008, which lead to a reduction in temporary employment and to a positive effect on overall job satisfaction on survivors' employees due to other's unemployment, especially due to a revalorization in the social support dimension. Lastly, labour policies are imposed to the regional governments at the Spanish State so that regional labour markets cannot adapt according to the needs and interest of their economy, which may be very different to the other regions. For instance, there is a need for a reorganization of the working time arrangements aimed at diminishing presentism, increase productivity, job satisfaction and health outcomes.

In summary, job satisfaction scarcely confounds the adverse health effects of long working hours but modifies the health risks with differences by gender. The results suggest that voluntariness in long hours can inhibit adverse effects on health status. For employees changing to longer work hours, a decrease in job satisfaction may suggest a health risk.

\section{Conflict of interest}

Authors declare no conflict of interest 


\section{References}

Ai, C., \& Norton, E. C. (2003). Interaction terms in logit and probit models. Economics Letters, 80, 123-129. https://doi.org/10.1016/S0165-1765(03)00032-6

Artazcoz, L., Cortès, I., Borrell, C., Escribà-Agüir, V., \& Cascant, L. (2007). Gender perspective in the analysis of the relationship between long workhours, health and health-related behavior. Scandinavian Journal of Work, Environment and Health, 33, 344-350. https://doi.org/10.5271/sjweh.1154

Baetschmann, G., Staub, K. E., \& Winkelmann, R. (2015). Consistent estimation of the fixed effects ordered logit model. Journal of the Royal Statistical Society. Series A: Statistics in Society. https://doi.org/10.1111/rssa.12090

Bannai, A., \& Tamakoshi, A. (2014). The association between long working hours and health: a systematic review of epidemiological evidence. Scand $J$ Work Environ Health, 40, 5-18. https://doi.org/10.5271/sjweh.3388\$\$r3388 [pii]

Bardasi, E., \& Francesconi, M. (2004). The impact of atypical employment on individual wellbeing: Evidence from a panel of British workers. Social Science and Medicine, 58, 1671-1688. https://doi.org/10.1016/S0277-9536(03)00400-3

Bardasi, E., \& Gornick, J. C. (2008). Working for less? Women’s Part-time Wage Penalties Across Countries. Feminist Economics, 14, 37-72. https://doi.org/10.1080/13545700701716649

Bartoll, X., Cortes, I., \& Artazcoz, L. (2014). Full- and part-time work: gender and welfare-type differences in European working conditions, job satisfaction, health status, and psychosocial issues. Scandinavian Journal of Work, Environment \& Health, 40(4), 370-379. https://doi.org/10.5271/sjweh.3429

Bartoll, X., \& Ramos, R. (2019). Quality of work, economic crisis, and temporary employment. International Journal of Manpower. https://doi.org/10.1108/IJM-062018-0177

Bassanini, \& Caroli. (2015). Is Work Bad for Health? The Role of Constraint versus Choice. Annals of Economics and Statistics, 13. https://doi.org/10.15609/annaeconstat2009.119-120.13

Beckers, D. G. J., Linden, D. Van Der, Smulders, P. G. W., Kompier, M. A. J., Veldhoven, M. J. P. M. Van, \& Yperen, N. W. Van. (1807). Working Overtime Hours : Relations with Fatigue, Work Motivation, and the Quality of Work. 12821289. https://doi.org/10.1097/01.jom.0000147210.95602.50

Benyamini, Y., Leventhal, E. A., \& Leventhal, H. (2000). Gender differences in processing information for making self-assessments of health. Psychosomatic Medicine, 62, 354-364. https://doi.org/10.1097/00006842-200005000-00009

Böckerman, P. (2004). Do Job Disamenities Raise Wages or Ruin Job Satisfaction? Do Job Disamenities Raise Wages or Ruin Job Satisfaction ?*(Vol. 17, Issue 20).

Booth, A. L., Ours, J. C. Van, Journal, E., \& Ours, C. Van. (2008). Job Satisfaction and Family Happiness : The Part-Time Work Puzzle. The Economic Journal, 118(526), 77-99. https://doi.org/10.1111/j.1468-0297.2007.02117.x

Booth, A. L., \& van Ours, J. C. (2013). Part-time jobs: What women want? Journal of Population Economics, 26, 263-283. https://doi.org/10.1007/s00148-012-0417-9

Brant, R. (1990). Assessing Proportionality in the Proportional Odds Model for Ordinal 
Logistic Regression. Biometrics, 46, 1171. https://doi.org/10.2307/2532457

Clark, A. E. (1997). Job satisfaction and gender: Why are women so happy at work? In Labour Economics (Vol. 4). https://doi.org/10.1016/S0927-5371(97)00010-9

Clark, A. E. (1998). Measures of Job Satisfaction. 34.

Clark, A. E. (2001). What really matters in a job? Hedonic measurement using quit data. Labour Economics, 8, 223-242. https://doi.org/10.1016/S0927-5371(01)00031-8

Clark, A. E., \& Oswald, A. J. (1996). Satisfaction and comparison income. Journal of Public Economics, 61, 359-381. https://doi.org/10.1016/0047-2727(95)01564-7

Cottini, E., \& Lucifora, C. (2010). Mental Health and Working Conditions in European Countries. 4717.

D’Addio, A. C., Eriksson, T., \& Frijters, P. (2007). An analysis of the determinants of job satisfaction when individuals' baseline satisfaction levels may differ. Applied Economics. https://doi.org/10.1080/00036840600707357

Datta Gupta, N., \& Kristensen, N. (2008). Work environment satisfaction and employee health: Panel evidence from Denmark, France and Spain, 1994-2001. European Journal of Health Economics, 9, 51-61. https://doi.org/10.1007/s10198-007-00376

DeSalvo, K. B., Bloser, N., Reynolds, K., He, J., \& Muntner, P. (2006). Mortality prediction with a single self-rated health question. Journal of General Internal Medicine, 21, 267-275. https://doi.org/10.1111/j.1525-1497.2005.0291.x

Díaz-Chao, A., Ficapal-Cusí, P., \& Torrent-Sellens, J. (2014). Workplace or working environment? Job quality and economic crisis in Spain (No. WP14-003; IN3 Working Paper Series).

Dinh, H., Strazdins, L., \& Welsh, J. (2017). Hour-glass ceilings: Work-hour thresholds, gendered health inequities. Social Science and Medicine, 176, 42-51. https://doi.org/10.1016/j.socscimed.2017.01.024

Dolbier, C. L., Webster, J. A., McCalister, K. T., Mallon, M. W., \& Steinhardt, M. A. (2005). Reliability and validity of a single-item measure of job satisfaction. American Journal of Health Promotion, 19, 194-198. https://doi.org/10.4278/0890-1171-19.3.194

Faragher, E. B., Cass, M., \& Cooper, C. L. (2005). The relationship between job satisfaction and health: a meta-analysis. Occupational and Environmental Medicine, 62, 105-112. https://doi.org/10.1136/oem.2002.006734

Ferrer-i-carbonell, A., \& Frijters, P. (2004). HOW IMPORTANT IS METHODOLOGY FOR THE ESTIMATES OF THE DETERMINANTS OF HAPPINESS ?*. 114(1997), 641-659.

Fischer, J. A. V, \& Sousa-Poza, A. (2009). Does job satisfaction improve the health of workers? New evidence using panel data and objective measures of health. Health Economics, 18, 71-89. https://doi.org/10.1002/hec.1341

Frey, B. S. (2008). Happiness: A Revolution in Economics. In Society. https://doi.org/10.1007/s12115-009-9211-z

Fujino, Y., Horie, S., Hoshuyama, T., Tsutsui, T., \& Tanaka, Y. (2006). A systematic review of working hours and mental health burden. Sangyo Eiseigaku Zasshi $=$ Journal of Occupational Health, 48. https://doi.org/10.1539/sangyoeisei.48.87 
Ganster, D. C., Rosen, C. C., \& Fisher, G. G. (2018). Long Working Hours and Wellbeing: What We Know, What We Do Not Know, and What We Need to Know. Journal of Business and Psychology, 33, 25-39. https://doi.org/10.1007/s10869016-9478-1

Green, F., \& Mostafa, T. (2010). JOB QUALITY INDICES FOR EUROPE. A Report Based On The Fifth European Working Conditions Survey.

Hodson, R. (1989). GENDER DIFFERENCES IN JOB SATISFACTION: Why Aren't Women More Dissatisfied? Sociological Quarterly, 30, 385-399. https://doi.org/10.1111/j.1533-8525.1989.tb01527.x

Holman, D., \& McClelland, C. (2011). Job quality in Growing and Declining Economic Sectors of the EU. In Work and Life Quality in New \& Growing Jobs.

Hora, G. P. R., Júnior, R. R., \& Souza, M. A. De. (2018). State of the art of job satisfaction measures: A systematic review. In Trends in Psychology. https://doi.org/10.9788/TP2018.2-16En

Judge, T. A., Heller, D., \& Mount, M. K. (2002). Five-factor model of personality and job satisfaction: A meta-analysis. Journal of Applied Psychology, 87, 530-541. https://doi.org/10.1037//0021-9010.87.3.530

Kivimäki, M., Jokela, M., Nyberg, S. T., Singh-Manoux, A., Fransson, E. I., Alfredsson, L., Bjorner, J. B., Borritz, M., Burr, H., Casini, A., Clays, E., De Bacquer, D., Dragano, N., Erbel, R., Geuskens, G. A., Hamer, M., Hooftman, W. E., Houtman, I. L., Jöckel, K. H., ... Virtanen, M. (2015). Long working hours and risk of coronary heart disease and stroke: A systematic review and meta-analysis of published and unpublished data for 603838 individuals. The Lancet, 386, 17391746. https://doi.org/10.1016/S0140-6736(15)60295-1

Manning, A., \& Petrongolo, B. (2008). The part-time pay penalty for women in britain. Economic Journal, 118. https://doi.org/10.1111/j.1468-0297.2007.02115.x

Mora, T. (2008). The effects of working conditions on health status : Simultaneous decisions on health and job satisfaction domains. Revista de Economía Laboral.

Muris, C. (2017). Estimation in the fixed-effects ordered logit model. Review of Economics and Statistics. https://doi.org/10.1162/REST_a_00617

Ng, T. W. H., \& Feldman, D. C. (2008). Long work hours: a social identity perspective on meta-analysis data. Journal of Organizational Behavior, 29, 853-880. https://doi.org/10.1002/job.536

Norton, E. C., \& Wang, H. (2004). Computing interaction effects and standard errors in logit and probit models. 2, 154-167.

O’Dorchai, S., Plasman, R., \& Rycx, F. (2007). The part-time wage penalty in European countries: how large is it for men? International Journal of Manpower, 28, 571603. https://doi.org/10.1108/01437720710830061

Perales, F., \& Tomaszewski, W. (2016). Happier with the Same: Job Satisfaction of Disadvantaged Workers. British Journal of Industrial Relations. https://doi.org/10.1111/bjir.12152

Robone, S., Jones, A. M., \& Rice, N. (2011). Contractual conditions, working conditions and their impact on health and well-being. European Journal of Health Economics, 12, 429-444. https://doi.org/10.1007/s10198-010-0256-0

Rodriguez, E. (2002). Marginal employment and health in Britain and Germany: Does 
unstable employment predict health? Social Science and Medicine, 55, 963-979. https://doi.org/10.1016/S0277-9536(01)00234-9

Seaman, S. R., \& White, I. R. (2013). Review of inverse probability weighting for dealing with missing data. In Statistical Methods in Medical Research. https://doi.org/10.1177/0962280210395740

Siegrist, J. (1996). Adverse Health Effects of High-Effort/Low-Reward Conditions. Journal of Occupational Health Psychology House Karasek \& Theorell La Ferla \& Levi, 1, 27-41. https://doi.org/10.1037/1076-8998.1.1.27

Simon, J. G., De Boer, J. B., Joung, I. M. A., Bosma, H., \& Mackenbach, J. P. (2005). How is your health in general? A qualitative study on self-assessed health. European Journal of Public Health, 15, 200-208. https://doi.org/10.1093/eurpub/cki102

Sousa-Poza, A., \& Sousa-Poza, A. A. (2000). Well-being at work: a cross-national analysis of the levels and determinants of job satisfaction. The Journal of SocioEconomics, 29, 517-538. https://doi.org/10.1016/S1053-5357(00)00085-8

Sparks, K., Cooper, C., Fried, Y., \& Shirom, A. (1997). The effects of hours of work on health: A meta-analytic review. Journal of Occupational and Organizational Psychology, 70, 391-408. https://doi.org/10.1111/j.2044-8325.1997.tb00656.x

Tangian, A. (2007). Analysis of the third European survey on working conditions with composite indicators. European Journal of Operational Research, 181, 468-499. https://doi.org/10.1016/j.ejor.2006.05.038

van der Hulst, M. (2003). Long workhours and health. In Scandinavian Journal of Work, Environment and Health (Vol. 29, pp. 171-188). https://doi.org/10.5271/sjweh.720

van der Meer, P. H., \& Ringdal, K. (2009). Flexibility practices, wages and productivity: Evidence from Norway. Personnel Review. https://doi.org/10.1108/00483480910978036

van Saane, N., Sluiter, J. K., Verbeek, J. H. a M., \& Frings-Dresen, M. H. W. (2003). Reliability and validity of instruments measuring job satisfaction--a systematic review. Occupational Medicine, 53, 191-200. https://doi.org/10.1093/occmed/kqg038

Wanous, J. P., Reichers, A. E., \& Hudy, M. J. (1997). Overall Job Satisfaction: How Good Are Single-Item Measures? Journal of Applied Psychology, 82, 247-252. https://doi.org/10.1037/0021-9010.82.2.247

Watanabe, K., Imamura, K., \& Kawakami, N. (2016). Working hours and the onset of depressive disorder: A systematic review and meta-analysis. In Occupational and Environmental Medicine (Vol. 73, pp. 877-884). https://doi.org/10.1136/oemed2016-103845

Williams, R. (2006). Generalized ordered logit/partial proportional odds models for ordinal dependent variables. Stata Journal, 6, 58-82. https://doi.org/st0097 
Table 1. Selected descriptive statistics.

\begin{tabular}{|c|c|c|c|c|c|c|}
\hline \multicolumn{2}{|c|}{} & & \multicolumn{3}{|c|}{ Self-perceived health } & Job satisfaction \\
\hline Working hours & $\%$ & & Excellent & Good & Poor & \% above median \\
\hline & & & & & & \\
\hline Men (N=1513) & 100 & & 16.0 & 66.6 & 17.4 & 43.6 \\
\hline$\leq 20$ & 3.2 & 18.5 & 54.4 & 27.1 & 48.2 \\
\hline $21-34$ & 4.0 & 10.0 & 69.6 & 20.4 & 48.8 \\
\hline $35-40$ & 82.1 & 16.2 & 67.2 & 17.6 & 67.1 \\
\hline $41-47$ & 6.4 & 15.7 & 65.3 & 19.0 & 40.7 \\
\hline$\geq 48$ & 4.3 & 17.0 & 67.6 & 15.4 & \\
\hline & & & & & 58.8 \\
\hline Women (N=1727) & & 14.1 & 63.8 & 22.1 & 56.8 \\
\hline$\leq 20$ & 11.6 & 14.6 & 66.1 & 19.3 & 46.3 \\
\hline $21-34$ & 16.8 & & 17.6 & 56.4 & 26.0 & 42.5 \\
\hline $35-40$ & 68.4 & 13.8 & 65.3 & 20.9 & 33.3 \\
\hline $41-47$ & 1.7 & & 0.9 & 67.4 & 31.7 & \\
\hline$\geq 48$ & 1.5 & & 1.0 & 52.5 & 46.5 & \\
\hline
\end{tabular}

Table 2. Job satisfaction and working hours per week as predictors of change in poor self-perceived health, Catalonia 2005-09.

\begin{tabular}{|c|c|c|c|c|c|c|}
\hline & \multicolumn{2}{|c|}{ Base model } & \multicolumn{2}{|c|}{ Adjusted model } & \multicolumn{2}{|c|}{ Interaction model } \\
\hline & coeff. & $\mathrm{sd}$ & coeff. & $\mathrm{sd}$ & coeff. & sd \\
\hline \multicolumn{7}{|l|}{ Men } \\
\hline$\leq 20 \mathrm{~h} / \mathrm{w}$ & -0.07 & 0.08 & -0.08 & 0.08 & -0.07 & 0.08 \\
\hline $21-34 \mathrm{~h} / \mathrm{w}$ & 0.12 & 0.07 & 0.11 & 0.07 & 0.10 & 0.07 \\
\hline $35-40 \mathrm{~h} / \mathrm{w}$ & ref. & & ref. & & ref. & \\
\hline $41-47 \mathrm{~h} / \mathrm{w}$ & $0.11 *$ & 0.51 & $0.13 *$ & 0.05 & $0.12 *$ & 0.05 \\
\hline$\geq 48 \mathrm{~h} / \mathrm{w}$ & $-0.17^{*}$ & 0.69 & $-0.16^{*}$ & 0.07 & $-0.16^{*}$ & 0.07 \\
\hline Job sat. (js) & & & $-0,16 * * *$ & 0.04 & $-0.20 * * *$ & 0.04 \\
\hline$\leq 20 \mathrm{~h} / \mathrm{w} * \mathrm{js}$ & & & & & 0.27 & 0.26 \\
\hline $21-34 \mathrm{~h} / \mathrm{w} * \mathrm{js}$ & & & & & 0.15 & 0.20 \\
\hline $41-47 \mathrm{~h} / \mathrm{w} * \mathrm{js}$ & & & & & $0.31 *$ & 0.13 \\
\hline$\geq 48 \mathrm{~h} / \mathrm{w} * \mathrm{js}$ & & & & & 0.03 & 0.17 \\
\hline \multicolumn{7}{|l|}{ Women } \\
\hline$\leq 20 \mathrm{~h} / \mathrm{w}$ & $-0.11 *$ & 0.04 & $-0,11^{*}$ & 0.04 & $-0.11 *$ & 0.04 \\
\hline $21-34 \mathrm{~h} / \mathrm{w}$ & -0.01 & 0.03 & -0.01 & 0.03 & -0.01 & 0.03 \\
\hline $35-40 \mathrm{~h} / \mathrm{w}$ & ref. & & ref. & & ref. & \\
\hline $41-47 \mathrm{~h} / \mathrm{w}$ & $0.21 *$ & 0.09 & $0.22 *$ & 0.09 & $0.26 * *$ & 0.09 \\
\hline$\geq 48 \mathrm{~h} / \mathrm{w}$ & 0.12 & 0.09 & 0.12 & 0.09 & 0.11 & 0.11 \\
\hline Job sat. (js) & & & 0.03 & 0.04 & 0.04 & 0.05 \\
\hline$\leq 20 \mathrm{~h} / \mathrm{w} *$ js & & & & & 0.11 & 0.12 \\
\hline $21-34 \mathrm{~h} / \mathrm{w} *$ js & & & & & -0.16 & 0.10 \\
\hline $41-47 \mathrm{~h} / \mathrm{w} *$ js & & & & & $0.51 \dagger$ & 0.27 \\
\hline$\geq 48 \mathrm{~h} / \mathrm{w} \quad *$ js & & & & & -0.06 & 0.22 \\
\hline
\end{tabular}

$\dagger$ p-value $<0.10 ;^{*}$ p-value $<0.05 ;{ }^{* *}$ p-value $<0.01 ; * * *$ p-value $<0.001$

sd: standard deviation

Adjusted by age, civil status, children (<16), type of family, education level, place of birth, type of contract, occupation, household net equivalent income, firm economic activity, municipality size, year, lagged health, health at base year. 
Table 3. Distribution and ordered marginal estimates for transitions to poorer self-perceived health of transitions in working hours and job satisfaction, Catalonia 2005-09.

\begin{tabular}{|c|c|c|c|c|c|c|}
\hline & \multicolumn{2}{|c|}{ Women } & \multicolumn{2}{|c|}{$\begin{array}{c}\text { Men } \\
(\mathrm{N}=1336)\end{array}$} & \multicolumn{2}{|c|}{$\begin{array}{c}\text { Women } \\
(\mathrm{N}=1509)\end{array}$} \\
\hline & $\%$ & $\%$ & coeff. & sd & coeff. & sd \\
\hline \multicolumn{7}{|l|}{$\begin{array}{l}\text { Transition to } \\
\text { Equal hours and }\end{array}$} \\
\hline $\begin{array}{l}\text { more job satisfaction } \\
\text { less job satisfaction }\end{array}$ & $\begin{array}{l}37.9 \\
40.4 \\
\end{array}$ & $\begin{array}{l}36.7 \\
35.4 \\
\end{array}$ & $\begin{array}{c}\text { reference } \\
0.58^{*} \\
\end{array}$ & 0.03 & $\begin{array}{c}\text { reference } \\
0.03 \\
\end{array}$ & 0.02 \\
\hline \multicolumn{7}{|l|}{ More hours and } \\
\hline $\begin{array}{l}\text { more job satisfaction } \\
\text { less job satisfaction }\end{array}$ & $\begin{array}{l}4.9 \\
4.8 \\
\end{array}$ & $\begin{array}{l}7.2 \\
6.3 \\
\end{array}$ & $\begin{array}{l}-0.04 \\
0.21 *\end{array}$ & $\begin{array}{l}0.04 \\
0.09 \\
\end{array}$ & $\begin{array}{l}-0.08^{*} \\
0.11^{*}\end{array}$ & $\begin{array}{l}0.03 \\
0.03\end{array}$ \\
\hline \multicolumn{7}{|l|}{ Less hours and } \\
\hline $\begin{array}{l}\text { more job satisfaction } \\
\text { less job satisfaction }\end{array}$ & $\begin{array}{l}4.8 \\
7.2 \\
\end{array}$ & $\begin{array}{l}7.0 \\
7.4 \\
\end{array}$ & $\begin{array}{c}-0.001 \\
0.001 \\
\end{array}$ & $\begin{array}{l}0.05 \\
0.05 \\
\end{array}$ & $\begin{array}{l}-0.02 \\
-0.01 \\
\end{array}$ & $\begin{array}{l}0.03 \\
0.04 \\
\end{array}$ \\
\hline
\end{tabular}

${ }^{*}$ p-value $<0.05 ;{ }^{* *}$ p-value $<0.01 ; * * *$ p-value $<0.001$

sd: standard deviation

Adjusted for changes in temporary employment. 


\section{Annex}

$\underline{\text { Table A1. Descriptive statistics }}$

\begin{tabular}{|c|c|c|c|c|}
\hline & \multicolumn{2}{|c|}{$\begin{array}{c}\text { Men } \\
\mathrm{N}=1513\end{array}$} & \multicolumn{2}{|c|}{$\begin{array}{l}\text { Women } \\
\mathrm{N}=1727\end{array}$} \\
\hline & $\%$ & s.d & $\%$ & s.d \\
\hline \multicolumn{5}{|l|}{ Age } \\
\hline $25-45$ & 60.0 & 49.0 & 61.5 & 48.7 \\
\hline $46-64$ & 40.0 & 49.0 & 38.5 & 48.7 \\
\hline Non-married & 30.4 & 46.0 & 38.8 & 48.7 \\
\hline \multicolumn{5}{|l|}{ Children $(<16)$} \\
\hline None & 28.6 & 45.2 & 57.2 & 49.5 \\
\hline One & 23.5 & 42.4 & 26.7 & 44.3 \\
\hline Two & 36.8 & 48.2 & 8.0 & 27.1 \\
\hline Three or more & 11.1 & 31.4 & 8.1 & 27.3 \\
\hline \multicolumn{5}{|l|}{ Type of family } \\
\hline Couple with children and others & 64.0 & 48.0 & 30.5 & 46.1 \\
\hline Couple without children & 24.8 & 43.2 & 25.1 & 43.4 \\
\hline Single & 8.2 & 27.4 & 36.3 & 48.1 \\
\hline Single-parent & 3.1 & 17.3 & 8.0 & 27.2 \\
\hline \multicolumn{5}{|l|}{ Education level } \\
\hline University & 33.0 & 47.0 & 49.9 & 50.0 \\
\hline Secondary & 36.8 & 48.2 & 25.9 & 43.8 \\
\hline Primary or less & 30.2 & 45.9 & 24.2 & 42.8 \\
\hline \multicolumn{5}{|l|}{ Place of birth } \\
\hline Catalonia & 64.9 & 47.7 & 68.2 & 46.6 \\
\hline Rest of Spain & 20.5 & 40.4 & 18.7 & 39.0 \\
\hline Others & 14.6 & 35.3 & 13.1 & 33.8 \\
\hline \multicolumn{5}{|l|}{ Type of contract } \\
\hline Permanent & 81.1 & 39.2 & 76.2 & 42.6 \\
\hline Temporary & 14.9 & 35.7 & 18.8 & 39.1 \\
\hline Others & 1.2 & 11.0 & 2.4 & 15.2 \\
\hline Missing & 2.7 & 16.3 & 2.6 & 16.0 \\
\hline \multicolumn{5}{|l|}{ Occupation } \\
\hline Manager & 20.6 & 40.5 & 18.1 & 38.5 \\
\hline Technician & 25.0 & 43.3 & 34.7 & 47.6 \\
\hline Administrative & 7.8 & 26.9 & 18.2 & 38.6 \\
\hline Shopkeeper & 2.9 & 16.7 & 14.0 & 34.7 \\
\hline Qualified worker & 22.1 & 41.5 & 2.4 & 15.3 \\
\hline Machine operator & 11.5 & 31.9 & 2.0 & 14.1 \\
\hline Non-qualified worker & 9.8 & 29.7 & 9.8 & 29.7 \\
\hline Missing & 0.3 & 5.6 & 0.9 & 9.2 \\
\hline \multicolumn{5}{|l|}{ Household equivalent net income } \\
\hline Low & 16.0 & 36.6 & 35.2 & 47.7 \\
\hline Medium & 36.7 & 36.7 & 32.3 & 46.8 \\
\hline High & 47.3 & 47.3 & 32.5 & 46.8 \\
\hline \multicolumn{5}{|l|}{ Firm economic activity } \\
\hline Agriculture/fisheries/extraction & 1.2 & 11.0 & 1.1 & 10.4 \\
\hline Manufacturing/production/distribution & 30.9 & 46.2 & 11.3 & 31.7 \\
\hline Construction & 10.8 & 31.0 & 1.4 & 11.9 \\
\hline Commerce and repair & 10.6 & 30.8 & 8.4 & 27.7 \\
\hline Hostelry & 1.8 & 13.3 & 4.0 & 19.7 \\
\hline Transport & 8.1 & 27.4 & 6.5 & 24.6 \\
\hline Financial mediation and Real estate & 13.6 & 34.3 & 14.3 & 35.0 \\
\hline PA/Education/Health & 20.5 & 40.4 & 47.5 & 50.0 \\
\hline Others & 1.9 & 13.7 & 5.1 & 22.0 \\
\hline Missing & 0.5 & 6.9 & 0.3 & 5.8 \\
\hline \multicolumn{5}{|l|}{ Inhabitants (thousands) } \\
\hline$<2$ & 4.0 & 19.6 & 5.1 & 21.9 \\
\hline $2-9.9$ & 10.5 & 30.6 & 10.7 & 30.9 \\
\hline $10-49.9$ & 24.0 & 42.7 & 23.4 & 42.3 \\
\hline $50-99$ & 14.0 & 34.7 & 12.0 & 32.5 \\
\hline $100-499$ & 24.5 & 43.0 & 19.2 & 39.4 \\
\hline$>500$ & 23.0 & 42.1 & 29.7 & 45.7 \\
\hline
\end{tabular}

Source: Social Inequalities Panel from the Jaume Bofill Foundation, Catalonia 2005-09. 
Table A2. Standardized factor loads and standard error for job satisfaction index

\begin{tabular}{|c|l|l|}
\hline & Load & s.e. \\
\hline Satisfaction with: & & \\
\hline$-\quad$ Salary & $0.4273^{* * *}$ & 0.015 \\
\hline$-\quad$ Support from colleges & $0.4254^{* * *}$ & 0.017 \\
\hline$-\quad$ Support from superiors & $0.5809^{* * *}$ & 0.016 \\
\hline$-\quad$ Workspace & $0.4918^{* * *}$ & 0.015 \\
\hline$-\quad$ Activity & $0.5318^{* * *}$ & 0.015 \\
\hline Covariance (support colleagues \& superiors) & $0.2562^{* * *}$ & 0.016 \\
\hline
\end{tabular}

Omitted output on variances

s.e: standar error

$* * * \mathrm{p}<0.001$ 